\title{
BB, Rat Strain
}

National Cancer Institute

\section{Source}

National Cancer Institute. BB, Rat Strain. NCI Thesaurus. Code C14394.

BB: The development of lymphocytic thyroiditis is not affected by iodine treatment according to Allen (1992), though Ebner et al (1992) found the opposite. Epitope specificities of collagen-induced arthritis studied by Cremer et al (1992). A lymphopenic, nondiabetic substrain BB-DR has very low T-cell numbers, depressed B-lymphocyte numbers and a complete absence of peripheral CD8+ T cells characteristics of the susceptible BB strain(Joseph et al 1993). Transfusing of BB-DR thymocytes into nude rats transfers the autoimmune insulin-dependent diabetes mellitus (Whalen et al 1995). 